\title{
Correction to: Clinical usefulness of eribulin as first- or second-line chemotherapy for recurrent HER2-negative breast cancer: a randomized phase II study (JBCRG-19)
}

\author{
Kenjiro Aogi ${ }^{1}$ (1) $\cdot$ Kenichi Watanabe ${ }^{2} \cdot$ Masahiro Kitada $^{3} \cdot$ Takafumi Sangai $^{4} \cdot$ Shoichiro Ohtani $^{5} \cdot$ Tomoyuki Aruga $^{6}$. \\ Hidetoshi Kawagichi $^{7}$ - Tomomi Fujisawa ${ }^{8}$. Shigeto Maeda ${ }^{9} \cdot$ Takashi Morimoto $^{10} \cdot$ Nobuaki Sato $^{11}$. \\ Shintaro Takao ${ }^{12} \cdot$ Satoshi Morita ${ }^{13} \cdot$ Norikazu Masuda $^{14} \cdot$ Masakazu Toi $^{15} \cdot$ Shinji Ohno $^{16}$
}

Published online: 27 May 2021

(c) The Author(s) 2021

\section{Correction to: International Journal of Clinical Oncology https://doi.org/10.1007/s10147-021-01920-0}

In the original publication, the name of the fourth author should be: Takafumi Sangai and his affiliation should be:

Department of Breast and Thyroid Surgery, Chiba University Hospital, Chiba, Japan

The corrected name and affiliation are given in this correction.
Open Access This article is licensed under a Creative Commons Attribution 4.0 International License, which permits use, sharing, adaptation, distribution and reproduction in any medium or format, as long as you give appropriate credit to the original author(s) and the source, provide a link to the Creative Commons licence, and indicate if changes were made. The images or other third party material in this article are included in the article's Creative Commons licence, unless indicated otherwise in a credit line to the material. If material is not included in the article's Creative Commons licence and your intended use is not permitted by statutory regulation or exceeds the permitted use, you will need to obtain permission directly from the copyright holder. To view a copy of this licence, visit http://creativecommons.org/licenses/by/4.0/.

Publisher's Note Springer Nature remains neutral with regard to jurisdictional claims in published maps and institutional affiliations.

8 Department of Breast Oncology, Gunma Prefectural Cancer Center, Ohta, Japan

9 Department of Surgery, National Hospital Organization Nagasaki Medical Center, Nagasaki, Japan

10 Department of Breast Surgery, Yao Municipal Hospital, Osaka, Japan

11 Department of Breast Oncology, Niigata Cancer Center Hospital, Niigata, Japan

12 Department of Breast Surgery, Hyogo Cancer Center Hospital, Kobe, Japan

13 Department of Biomedical Statistics and Bioinformatics, Graduate School of Medicine, Kyoto University, Kyoto, Japan

14 Department of Surgery, Breast Oncology, National Hospital Organization Osaka National Hospital, Osaka, Japan

15 Department of Breast Surgery, Graduate School of Medicine, Kyoto University, Kyoto, Japan

16 Breast Oncology Center, The Cancer Institute Hospital of Japanese Foundation for Cancer Research, Tokyo, Japan 